\title{
Annotations
}

\section{Night calls}

The telephone changed the lives of patients and their doctors in Canada. The text below gives a memorable picture of the role that the telephone and the operator played in one doctor's home in a small town in the Ig2os. The author is writing of his time as a young boy, when his father, Dr. John Francis Dunn, was the local doctor. Although the simplicity of a 2 digit number is now replaced with Io and the operator's voice is replaced by locating services, the difficulty of waking and responding to a telephone call remains constant over time.

$\mathrm{T}$ he doctor's house? Yes, number i9. One moment please." One moment was just enough for me to reflect on the mystery of how a person's voice could be carried over a wire, and in those days the mystery arose 40 times every day. Still, it was a comfort to know that anyone could pick up the phone, whether during the day or even in the middle of the night if the need be, and a lady known as The Operator would ask, "Number please?"

Telephone calls to most homes in the middle of the night usually brought sad tidings. But calls to the doctor's house came with regularity and all touched in some manner, for sadness or joy, the mystery of life.

In the doctor's house the phone sat in one corner of the table in my father's inside office, watching over prescription pads and a phone book. There were 2 sets of bells connected to the phone. One was downstairs, directly over the door to the big kitchen at the back of the house; the other, upstairs on the wall in the front hall, was near the door to our parents' bedroom and directly opposite the door to my own room. The telephone's summons therefore, could be heard in every part of the house.

It happened now and then that the doctor did not hear the phone in the night. And mother had I deaf ear. In the order of likelihood, therefore, that left me, in the bedroom directly over the inside office, and next closest to the

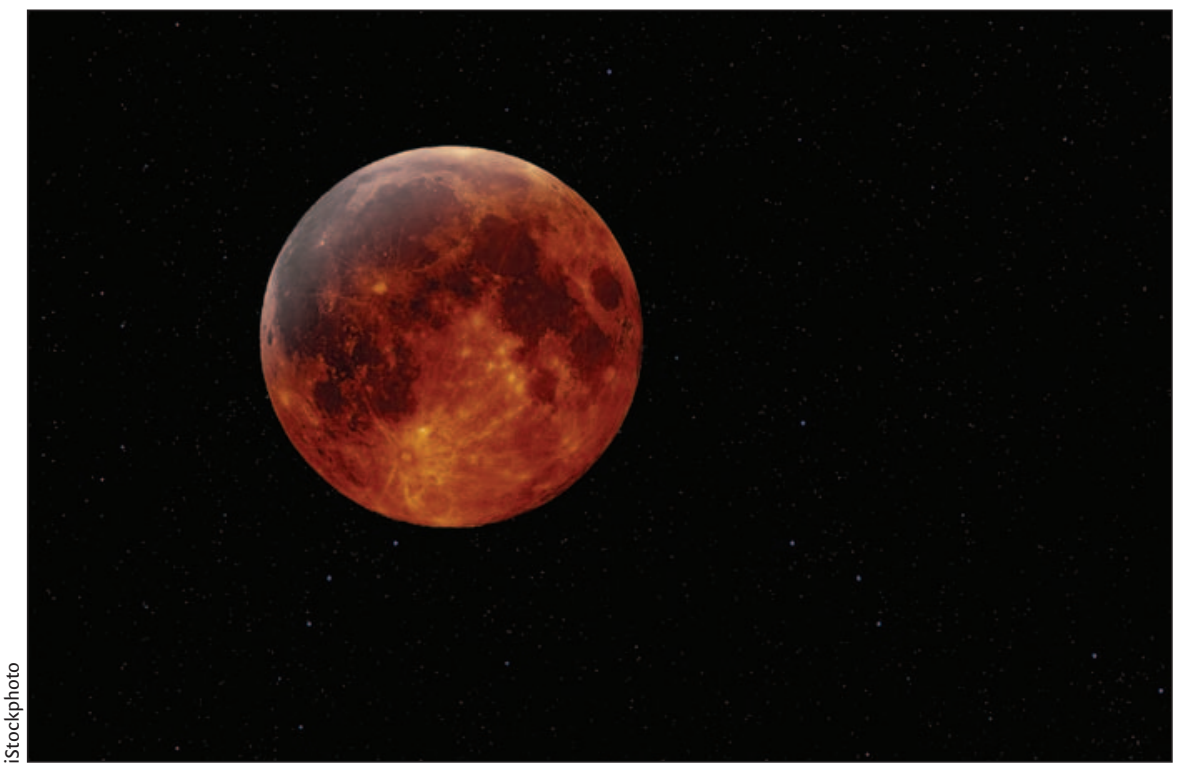

bell upstairs to ensure that the doctor was awakened to take the call.

The Operator always rang twice. The first, discreet, ordinary in all respects, was unexciting. The second, ro seconds later and twice as long, demanded attention. When even that got no response from my father, I'd get out of bed and go to the door opposite to say, "Dad, telephone's ringing."

With a leap from bed, he'd rush to the front stairway, and, in a kind of controlled crash, tumble down to the front hall, turn and make for the telephone in the inner office. With the receiver in one hand and the instrument in the other he would answer with one word, "Yes?"

Silence always followed, and in the silence, the mystery of the voice in the night deepened. The wondering lasted no more than 30 seconds and the silence ended with another brief response, "All right."

In contrast to the rush downstairs to take the call, his return was calm, careful, and subdued. The slow march, the walk upstairs, the landing on the upstairs hall, a quiet shuffling about in the bedroom, and another excursion to the lower hall. In a minute, even the final shreds of the night's interruption would close with the click of the latch on the office door, a whoosh of air as it closed behind, and the doctor was out on another call in the night. I'd sometimes wonder if he had ever thought of having an extension telephone located on his bedside table. That kind of arrangement, I thought, would reduce the danger of broken bones from one of his headlong flights downstairs. This idea I put before him by the firelight in the dining room one evening.

"I've thought of it many times," he replied without a moment's pause for deliberation. "But it just won't do. The way it is, I get to the phone awake and fully alert. But with the telephone upstairs there would always be the danger of answering only half awake, or, worse still, slipping back to sleep. I could never risk that," he concluded.

A kind of loneliness seemed to follow him out the door with the click of the latch. The little black satchel he carried in his hand held the same materials in all seasons: digitalis, chloroform, needles, threads, hypodermic syringe, scissors and bandages. They kept him company when fog filled the April predawn, when blood smeared the face of the September moon, and when sickness lay over the land in the time of the January thaw. Was a baby crying with colic and would not be comforted? Was 
a new young mother afraid and her baby impatient for the light? Or a greatgrandfather wanting to ask the doctor if it was time to call the priest?

We knew not.

But often we learned at 7:30 in the morning, at breakfast time as the family gathered for porridge and toast and honey and jam.

For it happened frequently that the latch on the office would again click, the air whoosh again with the door's closing. A powerful smell of ether would often rush ahead of the doctor into the kitchen. There it mingled easily with the smell and the sound of spoons rattling against the sides of porridge dishes. Mother, privileged to invade the boundaries of privacy by a few feet whenever she thought it absolutely urgent, took her cue from the ether.

"Well?" she asked.

An equally laconic response, "A boy," or, "A girl."

Factual as it was, that kind of response did not satisfy mother. It left her wanting to ask one more supplementary. "Everything all right?"

"Just fine."

Round the table there was consensus that the day had started. Of course someone else might pick up the telephone come night, and that someone too would hear The Operator ask, "Number please?" Again the sounds would come into the night: the latch on the office door would lift and click back into place again, and the doctor would be out to another home in town, to the hospital, or indeed miles distant to some place in the country.

"Number please?"

"Operator, can you get me the doctor, please?"

"One moment, I'll ring."

Night calls. House calls. Mysterious links in the chains of life.

- Excerpt from the memoir, Tales from the Doctor's House, 1995, John Patrick Dunn

\section{One thousand words}

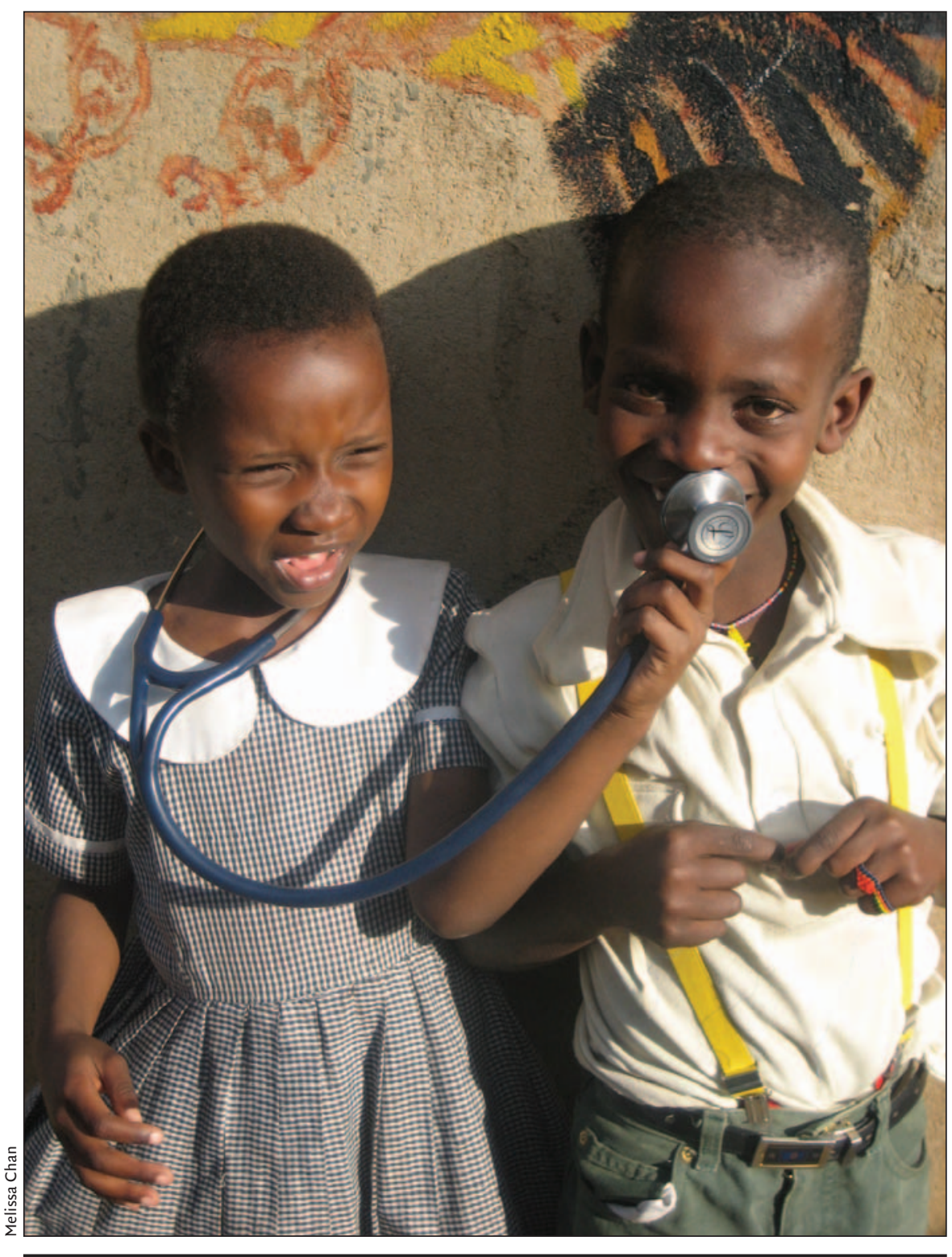

\section{Listening with the heart}

These "little doctors" are actually street children who are living at a shelter run by a humanitarian organization. Even with their broken past, these children were the most inspiring and uplifting people I have ever met. The hardest part of working with them was having to say goodbye when our project was finished. - Melissa Chan, medical student, McMaster University, Hamilton, Ont.

This photograph was among the winning entries in a contest that was held during the 2006 International Women and Children's Health Conference at McMaster University. Students in health sciences programs submitted photographs taken during their work in developing countries and in rural Ontario. 